\title{
COMPARISON OF TEMPERATURE CHANGE OF ONE- STEP SELF-ETCH ADHESIVE AND TWO-STEP SELF- ETCH ADHESIVE DURING PHOTO POLYMERIZATION OF COMPOSITE RESTORATION.
}

1. BDS

Department of Operative Dentistry Dr Israt ul Ebad Institute of Oral Health Sciences

Dow University of Health Sciences Karachi.

2. BDS, FCPS

Associate Professor and Chairman Department of Prosthodontics Institute of Dentistry Liaquat University of Medical \& Health Sciences, Jamshoro.

3. BDS, MSc

Assistant Professor

Department of Restorative Dental Sciences

College of Dentistry, King Khalid

University KSA.

4. BDS

Department of Prosthodontics Institute of Dentistry Liaquat University of Medical \& Health Sciences, Jamshoro.

Corresponding Address: Dr. Muhammad Rizwan Memon Department of Prosthodontics Institute of Dentistry, Liaquat University of Medical \& Health Sciences, Jamshoro.

muhammad.rizwan@lumhs.edu.pk

Article received on:

19/10/2018

Accepted for publication: $12 / 09 / 2019$

\begin{abstract}
Shakaib Ahmed', Muhammad Rizwan Memon², Muhammad Sibghatullah ${ }^{3}$, Irfan Khatri ${ }^{4}$
\end{abstract}
ABSTRACT... Objectives: To compare the mean temperature difference in one-step selfetch adhesive versus two-step-self etch adhesive during photo polymerization of composite. Study Design: Randomized control trial. Study Design: Was done at Department of Operative Dentistry Dr. Ishrat-ul-Ibad Khan Institute of Oral Health Sciences, Karachi. Period: From January 2017 to June 2017. Material \& Methods: A total of 92 human extracted maxillary and mandibulars third molar teeth were selected in this study. All discs were divided into two groups. 46 were treated with one-step self-etch adhesive and other 46 were treated with twostep self-etch adhesive. For both the study groups, the temperature was recorded at the start of procedure of photo polymerization and at the end of procedure. From the other side of the disc temperature was measured by non-contact infrared thermometer and recorded. Results: Male to female ratio 1.6:1. The age of the study population ranged from 20 years to 65 years, with mean age of the patients was $32.41 \pm 3.01$ years. Pre and post mean and the standard deviation (SD) of temperature was $31.95 \pm 2.14$ and $38.40 \pm 1.97$ in One-step self-etch adhesive and $31.91 \pm 2.25$ and $38.45 \pm 2.26$ in two-step-self-etch adhesive group respectively. Mean change was $6.45 \pm 0.78$ in One-step self-etch adhesive and 6.45 \pm 0.74 in two-step-self-etch adhesive group. Mean difference was not statistically significant between groups $(p=0.605)$. While within group comparison, mean temperature was significantly high in one-step self-etch adhesive and also in two-step-self-etch adhesive. Conclusion: It is concluded that dental practitioners should be aware of the risk of thermal insults to the pulp as a result of photo polymerization of resincontaining restorative materials, especially when caries-affected deep dentin is involved for longer periods.

Key words: $\quad$ One Step Self-etch Adhesive, Photo Polymerization, Two Step self-etch Adhesive.

Article Citation: Ahmed S, Memon MR, Sibghatullah M, Khatri I. Comparison of temperature change of one-step self-etch adhesive and two-step self-etch adhesive during photo polymerization of composite restoration. Professional Med J 2020; 27(1):5-10. DOI: 10.29309/TPMJ/2020.27.1.239

\section{INTRODUCTION}

Optimizing tooth form has always been the "Heart's Desire" of restorative surgeon for replacing the lost tooth anatomy and its functions. Since the advancement in the adhesive dentistry, composite resins are more acceptable form of restoration as compare to gold casts and amalgam. ${ }^{1}$ The longevity of composite resins with tooth structure depends on the mechanical interlocking, which is achieved by adhesives and photo polymerization. ${ }^{2}$

The primary purpose of adhesives is to produce adhesion between composite material and tooth surface. Currently, the self-etch adhesive system is used for adhesion that prevents over drying of dentine. ${ }^{2,3}$ For that purpose, new light cure units are constantly being introduced in the dental practice for the use of composite restoration. ${ }^{4}$ These units are needed to activate photo polymerization in which heat is generated either by exothermic reaction from adhesive or curing light itself that may cause damage to pulp., ${ }^{5,6}$

It is commonly believed that pulp may get damaged during dental procedures such as deep cavity preparation, laser bleaching and composite polymerization. ${ }^{7}$ In the literature related to the photo polymerization, the damage of the pulp was discussed. Munguia et al. ${ }^{8}$ Investigated 
the temperature changes of primary dentine at different distances. They concluded that halogen lamps cause production of more heat in materials than LED lamps, and the greatest rise is observed in micro hybrid flow resin when photo cured with the Optilux. In another instance, split tooth technique ${ }^{9}$ was introduced to check the pulpal temperature during photo polymerization. This study proposed that dentine bonding agent should be cured by low intensity curing lights while resin based composite can be cured by high intensity unit either by halogen or LED. ${ }^{9}$

\section{All of these studies showed that pulpal temperature changes during photo polymerization and their effect on dental pulp.} Nevertheless, self-etch adhesive system has been sparsely explored in the literature. Such as, Mousavinasab ${ }^{10}$ observed that light cured self-etching low shrinkage system primer and adhesive can prevent heat to pass to the pulp during light activation. They measured the mean and the standard deviation (SD) of temperature changes with primer and adhesive is $5.14 \pm 0.62$ and without primer and adhesive is $5.58 \pm 0.86$. They further addressed the comparison between one-step and two-step self-etch adhesive for mean temperature changes. However, previous studies have a small sample size. Further, we have climate differences, transportation of materials and morphological characteristics, which may vary within our population. Therefore, it is an opportunity for us to conduct a research in this area. Thus, the rationale of this study is to address the comparison between one-step and two-step self-etch adhesive for mean temperature changes during photo polymerization of composite restoration.

\section{MATERIAL \& METHODS}

Department of Operative Dentistry, Dr. Ishratul-Ibad Khan Institute of Oral Health Sciences, Karachi, January 2017 to June 2017. Ninety two human extracted third molar teeth were collected from the department of oral surgery at Dr. Ishratul-lbad khan Institute of Oral Health Sciences. As this study was done on extracted teeth so, there was no ethical approval or informed consent required for conduct of this study.
The inclusion criteria was patients came for teeth extracted for all age group both patients male and female patients, extracted maxillary and mandibulars third molar, Fully formed crown and roots (assessed clinically) and nonendodontically treated teeth. Badly broken crown and root will assessed clinically and excluded because they cannot cross sectioned properly to create dentinal disc, restored or endodontically treated teeth, teeth with desorption, perforation and hypo plastic and flourosis (clinically because of hypominerlized or hyperminerlized disc preparation) were excluded.

Each specimen collection was kept in saline water to prevent dehydration. ${ }^{8}$ Selected teeth were cleaned by scaling and polishing for the removal of bone fragments, calculus or any soft tissue attachment. Dentin discs measuring $2 \mathrm{~mm}$ in thickness was prepared from $2 \mathrm{~mm}$ below the Cement enamel junction of 92 extracted third molars teeth. ${ }^{6}$ First, each tooth was mounted in epoxy resin (Triplex Acryl, Ivoclar Vivadent, Schaan, Liechtenstein); then sections was prepared parallel to the long axis of each tooth with a diamond disc 4620 (DENTSPLY) under copious water irrigation in order to prevent overheating. ${ }^{10}$ Stainless steel ring with $5 \mathrm{~mm}$ diameter was prepared for $2 \mathrm{~mm}$ and $4 \mathrm{~mm}$ disc. These bands were spot welded for same thickness and diameter. Finally all discs were placed in saline until use. All discs were divided into two groups by lottery method. First group was one-step self-etch adhesive Adper ${ }^{\mathrm{Tm}}$ Single Bond Plus Adhesive and other was two-step selfetch adhesive OptibondXTRSelf-Etch, Light-Cure Universal Dental Adhesive. 2mm of composite restoration was applied and cured with LED light for 40 seconds and change in temperature was recorded by Non-contact infrared thermometer, which provide accuracy and reliability for temperature measurement..11,12 Thus, in this study, infrared thermometer device that is ST-812 was used for the measurement of temperature.

For both the study groups, the temperature was recorded at the start of procedure of photo polymerization and at the end of procedure. Furthermore, the mean change in temperatures 
was calculated by subtract the lower reading from higher reading of each specimen. During the procedure LED light was kept as near as possible to the discs. From the other side of the disc temperature was measured by non-contact infrared thermometer and recorded.

\section{RESULTS}

A total of 92 human extracted maxillary and mandibulars third molar teeth were selected in this study. All discs were divided into two groups. 46 were treated with one-step self-etch adhesive and other 46were treated with two-step self-etch adhesive. Out of 92 cases, 35(38.04\%) were female and $57(61.95 \%)$ male. Male to female ratio 1.6:1 (Figure-1). The age of the study population ranged from 20 years to 65 years, with mean age of the patients was $32.41 \pm 3.01$ years.

Pre and post mean and the standard deviation (SD) of temperature was $31.95 \pm 2.14$ and $38.40 \pm 1.97$ in One-step self-etch adhesive and $31.91 \pm 2.25$ and $38.45 \pm 2.26$ in two-step-selfetch adhesive group respectively. Mean change was $6.45 \pm 0.78$ in One-step self-etch adhesive and $6.45 \pm 0.74$ in two-step-self-etch adhesive group. Mean difference was not statistically significant between groups $(p=0.605)$ as shown in Table-l. While within group comparison, mean temperature was significantly high in one-step self-etch adhesive and also in two-step-self-etch adhesive as shown in Table-II.

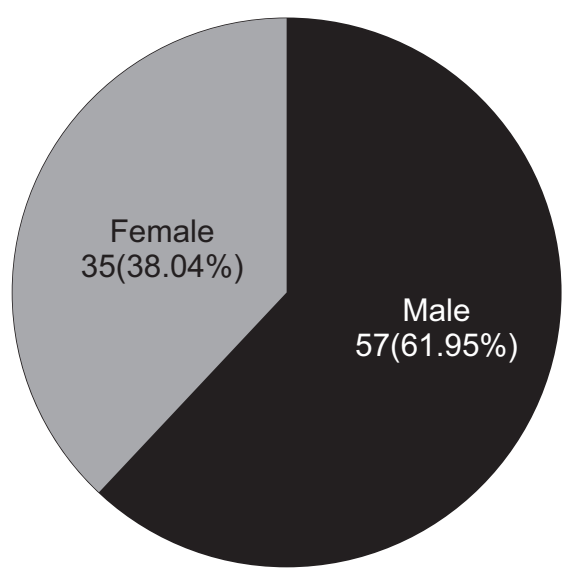

Figure-1. Gender distribution $\mathrm{N}=92$

\section{DISCUSSION}

Photopolymerization of dental adhesives and resin-based composite resins increases dentin temperature through exothermic resin polymerization process and the energy absorbed during light-curing. The rate of exothermic polymerization reaction and maximum temperature rise during the process is proportional to the irradiance of the light curing unit, chemical structure of the adhesive, and/ or the composite resin and the light conduction properties of composite resin. ${ }^{13-15}$

\begin{tabular}{|l|c|c|c|c|c|}
\hline \multirow{2}{*}{ Temperature } & \multicolumn{2}{|c|}{$\begin{array}{c}\text { One-step self-etch adhesive } \\
\mathbf{n = 4 6}\end{array}$} & \multicolumn{3}{c|}{$\begin{array}{c}\text { Two-step-self-etch adhesive } \\
\mathbf{n = 4 6}\end{array}$} \\
\cline { 2 - 6 } & Mean & Std. Deviation & Mean & Std. Deviation \\
\hline Before & 31.95 & 2.14 & 31.91 & 2.25 & 0.932 \\
\hline After & 38.40 & 1.97 & 38.45 & 2.26 & 0.918 \\
\hline Change & 6.45 & 0.78 & 6.54 & 0.74 & 0.605 \\
\hline
\end{tabular}

Table-I. Comparison of mean temperature between groups during photo polymerization of composite

\begin{tabular}{|c|c|c|c|c|}
\hline \multirow{2}{*}{ Temperature } & \multicolumn{2}{|c|}{$\begin{array}{l}\text { One-step self-etch adhesive } \\
\qquad n=46\end{array}$} & \multicolumn{2}{|c|}{$\begin{array}{l}\text { Two-step-self-etch adhesive } \\
\qquad n=46\end{array}$} \\
\hline & Mean & Std. Deviation & Mean & Std. Deviation \\
\hline After & 38.400 & 1.97 & 38.45 & 2.26 \\
\hline Change & 6.45 & 0.78 & 6.54 & 0.74 \\
\hline
\end{tabular}


Although dentin has a low thermal conductivity, the risk of pulp damage is high in deep composite restorations because dentinal tubules are more numerous and denser in deep cavities. As a result, irritation of the pulp due to heat depends on the extent and duration of temperature rise..$^{16,19}$

Studies have shown that the heat generated during restorative procedures might have a detrimental e $\square$ ect on dental pulp. There is still controversy over the $5.5 \circ \mathrm{C}$ threshold temperature rise for irreversible changes in the dental pulp. ${ }^{19,20}$ Dentin has been reported to have a low thermal conductivity; however, the risk of irreversible pulp damage is greater in deep cavities with minimal residual dentin thickness, in which there is a concomitant increase in tubular surface area. ${ }^{21} \mathrm{~A}$ large number of in vitro studies have been carried out to determine temperature rise during light-curing procedures of resinbased restorative materials; these studies have predominantly used ground or non-carious dentin substrates. ${ }^{22-25}$ However, in most clinical situations non-carious dentin is not encountered ${ }^{26}$ and carious dentin is generally restored. Carious dentin characteristically consists of infected and a $\square$ ected layers; the a $\square$ ected dentin layer is not usually removed during restorative procedures. ${ }^{27}$

In present study pre and post mean and the standard deviation (SD) of temperature was $31.95 \pm 2.14$ and $38.40 \pm 1.97$ in One-step selfetch adhesive and $31.91 \pm 2.25$ and $38.45 \pm 2.26$ in two-step-self-etch adhesive group respectively. Mean change was $6.45 \pm 0.78$ in One-step self-etch adhesive and $6.45 \pm 0.74$ in two-stepself-etch adhesive group. Mean difference was not statistically significant between groups $(p=0.605)$. Mousavinasab ${ }^{10}$ observed that light cured self-etching low shrinkage system primer and adhesive can prevent heat to pass to the pulp during light activation. They measured the mean and the standard deviation (SD) of temperature changes with primer and adhesive is $5.14 \pm 0.62$ and without primer and adhesive is $5.58 \pm 0.86$. They further addressed the comparison between one-step and two-step self-etch adhesive for mean temperature changes. There is consensus that temperature rise due to certain dental procedures threatens pulp vitality. ${ }^{28}$ It has also been postulated that visible light polymerization units might increase temperatures within the pulp chamber, irritating the pulp. ${ }^{29}$

An animal study by Zach and Cohen resulted in determination of a threshold temperature for irreversible pulp injury during application of external heat to a sound tooth: a $5.5 \circ \mathrm{C}$ intra pulpal temperature rise gave rise to necrosis in $15 \%$ of the pulps. ${ }^{20}$ Previous studies have shown that the extent of temperature depends on two factors: the exothermic polymerization reaction of composite resin during photo polymerization and the energy output of the light-curing unit. ${ }^{30-}$ 32 The results of the present study supported the hypothesis that longer photo polymerization times result in significantly greater temperature rise compared to shorter irradiation times.

Comparison of temperature changes in di $\square$ erent groups of the present study, particularly in the presence of demineralized dentin, which is very similar to clinical situations, shows that dental practitioners should be aware of the risk of thermal insults to the pulp as a result of photo polymerization of resin-containing restorative materials, especially when caries-a $\square$ ected deep dentin is involved for longer periods. In such conditions, a simple but very e\ective method for pulp protection is to use an e $\square$ ective cement base or lining material to reduce the intrapulpal temperature rise during light polymerization of composite resin. ${ }^{33}$

\section{CONCLUSION}

In present study there was no significant differences of pre and post mean temperature in One-step self-etch adhesive and in twostep-self-etch adhesive group. Comparison of temperature changes in different groups of the present study, particularly in the presence of demineralized dentin, which is very similar to clinical situations, shows that dental practitioners should be aware of the risk of thermal insults to the pulp as a result of photo polymerization of resin-containing restorative materials, especially when caries-affected deep dentin is involved for longer periods. 
Copyright $\odot 12$ Sep, 2019.

\section{REFERENCES}

1. Raghu R, Srinivasan R. Optimizing tooth form with direct posterior composite restorations. J Conserv Dent. 2011; 14(4):330-36.

2. Knobloch LA, Gailey D, Azer S, Johnston WM, Clelland $\mathrm{N}$, Kerby RE. Bond strengths of one- and two-step self-etch adhesive systems. J Prosthet Dent 2007; 97:216-22.

3. Bowen RL. Adhesive bonding of various materials to hard tooth tissues. II. Bonding to dentin promoted by a surface-active comonomer. J Dent Res, 1965; 44:895-902.

4. Nomoto R. Effect of light wave length on polymerization of light -cured resins. Dent Mater J. 1997; 16:60-73.

5. Xie $\mathrm{C}$, Wang ZY, He H, Han Y. In vitro pulp chamber temperature rise during fabrication of provisional restoration on different types of teeth. Int Chin J Dent. 2007; 7:69-74.

6. Uhl A, Volpel A, Sigusch BW. Influence of heat from light curing units and dental composite polymerization on cells in vitro. J Dent. 2006; 34(4):298-306.

7. Munguia AM, Gambus MA, Jimeno FG, Dalmau LJB. Temperature changes caused by light curing units on dentine of primary teeth. Eur J Paediatr Dent. 2011; 12(1):7-12.

8. Millen C, Ormond M, Richardson G, Santini A, Miletic $V$, Kew P. A Study of temperature rise in the pulp chamber during composite polymerization with different light-curing units. J Contemp Dent Pract 2007; (8)7:029-37.

9. Mousavinasab SM, Khoroushi M, Moharreri M. Temperature rise during primer, adhesive, and composite resin photo polymerization of a lowshrinkage composite resin under caries-like dentin lesions. ISRN Dent 2012 Epub ahead of print. DOI: $10.5402 / 2012 / 198351$.

10. Teran CG, Torrez-LJ, Teran-Miranda TE, Balderrama C, Shah NS, Villarroel P. Clinical accuracy of a noncontact infrared skin thermometer in paediatric practice. Child Care Health Dev. 2012; 38(4):471-6.

11. Hamilton PA, Marcos LS, Secic M. Performance of infrared ear and forehead thermometers: a comparative study in 205 febrile and afebrile children. J ClinNurs. 2013; 22:17-18.
12. Balic A, Thesleff I. Tissue Interactions Regulating Tooth Development and Renewal. Curr Top Dev Biol. 2015; 115:157-60.

13. Kinomoto Y, Torii M, Takeshige F, Ebisu S. Polymerization shrinkage stresses of resin-based composite restorations within beveled cavity preparations of Class I restorations. Am J Dent. 2003 Apr; 16(2):13943.

14. Silva APD, Cunha LAD, Pagani C, De MelloRode S. Temperature rise during adhesive and composite polymerization with di $\square$ erent light-curing sources. Minerva Stomatologica, 2010; 59(5):253-8.

15. Miletic V, Ivanovic V, Dzeletovic B, Lezaja M. Temperature changes in silorane-, ormocer-, and dimethacrylate based composite sand pulp chamber roof during light-curing. J Esthetic and Restorative Dentistry 2009; $21(2): 122-31$.

16. Leprince J, Devaux J, Mullier T, Vreven J, Leloup G. Pulpal-temperature rise and polymerization e $\square$ ciency of LED curing lights. Operative Dentistry 2010; 35(2):220- 230.

17. Miletic V, Ivanovic V, Dzeletovic B, Lezaja M. Temperature changes in silorane-, ormocer-, and dimethacrylate based composites and pulp chamber roof during light-curing," J Esthetic \& Restorative Dentistry, 2009; $21(2): 122-131$.

18. Ozturk B, Ozturk AN, Usumez A, Usumez S, Ozer F. Temperature rise during adhesive and resin composite polymerization with various light curing sources. Operative Dentistry 2004; 29(3):325-32.

19. Leprince J, Devaux J, Mullier T, Vreven J, Leloup G. Pulpal-temperature rise and polymerization e $\square$ ciency of LED curing lights. Operative Dentistry, 2010; 35(2):220- 230.

20. Zach, Cohen G. Pulp response to externally applied heat. Oral Surgery, Oral Medicine, Oral Pathology, 1965; 19(4):515-30.

21. Baldissara P, Catapano S, Scotti R. Clinical and histological evaluation of thermal injury thresholds in human teeth: A preliminary study. J Oral Rehabilitation, 1997; 24(11):791-801.

22. Stewardson DA, Shortall ACC, Harrington E, Lumley PJ. Hermal changes and cure depths associated with a high intensity light activation unit. J Dentistry 2004; 32(8):643-651.

23. Al-Qudah A, Mitchell CA, Biagioni PA, Hussey DL. The rmographic investigation of contemporary resin containing dental materials. J Dentistry, 2005; 33(7):593-602. 
24. Loureiro FH, Consani S, Guiraldo RD. Comparison between two methods to evaluate temperature changes produced by composite light curing units and polymerization techniques. Minerva Stomatologica 2011; 60(10):501-8.

25. Loney RW, Price RB. Temperature transmission of high-output light-curing units through dentin. Operative Dentistry, 2001; 26(5):516-20.

26. Nakajima M, Ogata M, Okuda M, Tagami J, Sano H, Pashley $\mathrm{DH}$. Bonding to caries-a $\square$ ected dentin using selfetching primers. Am J Dentistry, 1999; 12:309-14.

27. Nakajimam M, Sano $H$, Burrow MF. Tensile bond strength and SEM evaluation of caries-a $\square$ ected dentin using dentin adhesives. J Dental Rese, 1995; 74(10):1679-88.

28. Lloyd $\mathrm{CH}$, Brown EA. The heats of reaction and temperature rises associated with the setting of bonding resins. J Oral Rehabilitation, 1984; 11(4):319 24.

29. Taher NM, Al-Khairallah Y, Al-Aujan SH, Ad'dahash $M$. The e $\square$ ect of di $\square$ erent light-curing methods on temperature changes of dual polymerizing agents cemented to human dentin. J Contemporary Dental Practice, 2008; 9(2):57-64.
30. Knezevic A, Sariri K, Sovic I, Demoli N, Tarle Z. Shrinkage evaluation of composite polymerized with LED units using laser interferometry. Quintessence International, 2010; 41(5):417-425.

31. Mungura AM, Gambus MA, Jimeno FG, Dalmau LJB. Temperature changes caused by light curing units on dentine of primary teeth. Eur $\mathrm{J}$ Paediat Dentistry, $2011 ; 12(1): 7-12$.

32. da Silva EM, Penelas AG, Sim ̃ao MS, Filho JDN, Poskus LT, Guimar aes JGA. Influence of the degree of dentine mineralization on pulp chamber temperature increase during resin-based composite (RBC) lightactivation. J Dentistry 2010; 38(4):336-342.

33. Tosun G, Usumez A, Yondem I, Sener Y. Temperature rise under normal and caries-a $\square$ ected primary tooth dentin disks during polymerization of adhesives and resin-containing dental materials. Dental Materials J, 2008; $27(3): 466-470$.

\begin{tabular}{|c|c|c|c|}
\hline \multicolumn{4}{|c|}{ AUTHORSHIP AND CONTRIBUTION DECLARATION } \\
\hline Sr. \# & Author(s) Full Name & Contribution to the paper & Author(s) Signature \\
\hline 1 & Shakaib Ahmed & $\begin{array}{l}\text { Article designing and data } \\
\text { collection. }\end{array}$ & \\
\hline 2 & M. Rizwan Memon & $\begin{array}{l}\text { Article compiling and data } \\
\text { collection. }\end{array}$ & \\
\hline 3 & M. Sibghatullah & Discussion writing and data & \\
\hline 4 & Irfan Khatri & $\begin{array}{l}\text { collection. } \\
\text { Data collection. }\end{array}$ & grk \\
\hline
\end{tabular}

